\title{
Ethnic Health Care Advisors: A Good Strategy to Improve the Access to Health Care and Social Welfare Services for Ethnic Minorities?
}

\author{
Arlette E. Hesselink · Arnoud P. Verhoeff • \\ Karien Stronks
}

Published online: 29 August 2009

(C) The Author(s) 2009. This article is published with open access at Springerlink.com

\begin{abstract}
Empirical studies indicate that ethnic minorities have limited access to health care and welfare services compared with the host population. To improve this access, ethnic health care (HC) advisors were introduced in four districts in Amsterdam, the Netherlands. HC advisors work for all health care and welfare services and their main task is to provide information on health care and welfare to individuals and groups and refer individuals to services. Action research was carried out over a period of 2 years to find out whether and how this function can contribute to improve access to services for ethnic minorities. Information was gathered by semi-structured interviews, analysing registration forms and reports, and attending meetings. The function's implementation and characteristics differed per district. The ethnicity of the health care advisors corresponded to the main ethnic groups in the district: Moroccan and Turkish (three districts) and sub-Sahara African and Surinamese (one district). HC advisors reached many ethnic inhabitants $(n=2,224)$ through individual contacts. Half of them were referred to health care and welfare
\end{abstract}

A. E. Hesselink $(\square) \cdot$ A. P. Verhoeff

Department of Epidemiology and Health Promotion,

Public Health Service Amsterdam, P.O. Box 2200,

1000 CE Amsterdam, The Netherlands

e-mail: ahesselink@ggd.amsterdam.nl

A. P. Verhoeff

The Department of Sociology and Anthropology,

University of Amsterdam, Amsterdam, The Netherlands

K. Stronks

Professor of Social Medicine, Department of Social Medicine,

Academic Medical Center/University of Amsterdam,

Amsterdam, The Netherlands services. In total, 576 group classes were given. These were mostly attended by Moroccan and Turkish females. Outreach activities and office hours at popular locations appeared to be important characteristics for actually reaching ethnic minorities. Furthermore, direct contact with a well-organized back office seems to be important. $\mathrm{HC}$ advisors were able to reach many ethnic minorities, provide information about the health care and welfare system, and refer them to services. Besides adapting the function to the local situation, some general aspects for success can be indicated: the ethnic background of the HC advisor should correspond to the main ethnic minority groups in the district, HC advisors need to conduct outreach work, there must be a well-organized back office to refer clients to, and there needs to be enough commitment among professionals of local health and welfare services.

Keywords Community health worker .

Access to health care - Social welfare .

Ethnic minority groups $\cdot$ Public health $\cdot$ Action research

\section{Introduction}

Unequal access to health care and welfare services for nonWestern ethnic minorities are widely considered undesirable, but have nevertheless been demonstrated repeatedly [1-5]. Some studies even claim that limited access to health care resources is the most important contributing factor for ethnic disparities in health [4, 6]. Impaired access to care is in part caused by problems ethnic minorities have with the language of the host country, cultural differences in seeking and receiving care, mistrust of medical professionals, and lack of knowledge about the health care and welfare system [2, 3, 5, 7-11]. In addition, most ethnic 
minority groups are hard to reach for professionals; it is also difficult to reach them through the usual information routes used to inform the host population. This inequity calls for action, especially since the health care systems in the Netherlands and most other countries in the Western world aim to ensure good health care for their population according to individual needs and regardless of social position, gender, race, and ethnicity [8, 10, 12, 13].

Cultural competent interventions, like the introduction of ethnic community health workers have been proposed for improving care and access to care for ethnic minority groups [9]. Community health workers have the same ethnic background as the target (ethnic minority) groups so they know the language and culture and are aware of the specific problems ethnic minorities deal with. They work as liaisons between community members and health care providers, and have been evaluated positively [9, 14-19]. In practice, however, community health worker programmes vary. They are usually associated with specific health care providers to improve the quality of care by informing clients about specific topics like diabetes, psychosomatic problems, and emergency care $[1-6,19,20]$. In order to reach and inform more ethnic minorities about a broader spectrum of health care and welfare services and to help minorities find out where they need to go with their problems, we developed a new specialization for community workers: so-called health care advisors (HC advisors) conduct outreach work and work for all health care and welfare services. In this way, $\mathrm{HC}$ advisors are able to reach and inform ethnic minority groups who are otherwise hard to reach using the usual information routes.

To implement and develop the $\mathrm{HC}$ advisor function, a 2year pilot was initiated in four of the 14 districts in Amsterdam. During this pilot, each district developed its own version of the position in more detail, based on the context and the services in that district [21]. For this reason, the implementation and tasks of the HC advisors differed between the participating districts. Action research was carried out to support the development of the function position in the districts [22]. This approach provides the opportunity to compare the results between the four districts and describe if and under which conditions $\mathrm{HC}$ advisors can contribute in reaching and informing ethnic minority groups who are normally hard to reach and so improve their access to health care and welfare services. The research questions are:

1. How was the function of $\mathrm{HC}$ advisor implemented?

2. Who did the HC advisors reach and what was their production?

3. Which features are needed to make the function of $\mathrm{HC}$ advisor successful, in terms of the extent to which they reach 'hard to reach' groups?

\section{Methods}

To improve and develop the function of $\mathrm{HC}$ advisor and to create a basis for further implementation, participatory action research was carried out during a 2-year pilot $[22$, 23]. A total of four districts with an average of 155,742 inhabitants per district took part in the pilot study [24]. Data for our study were gathered using mixed methods, including quantitative data from registrations and qualitative date from semi-structured interviews, observations of group classes, analysing reports, and attending meetings [25]. Results were issued on an annual basis and upon request shared with the district council and the district steering committees for HC advisors. The steering committees were made up of stakeholders from health care, welfare, and migrant organizations in that district, who met on a regular basis to supervise the HC advisors. For this reason, for every year of the pilot, similar information was collected, analysed, and published in a report. The researcher also conducted interim presentations and consultations. Each district received one or two interim reports and one final evaluation report [26]. This sharing of information meant that districts were able to adapt the function based on the research results during the pilot period.

To answer the first research question, the initial document describing the project and other documents written by the district councils were gathered and analysed. The researcher attended meetings of the steering committees and studied the reports of the meetings. The researcher observed the HC advisors during various individual and group contacts. Furthermore, semi-structured interviews were carried out by the researcher with the $\mathrm{HC}$ advisors, their coordinators, and the stakeholders in the district councils.

To study the characteristics of the individuals reached by the HC advisors and the activities they carried out, HC advisors filled out registration forms with information about the individual and group contacts. During the individual contacts, information was recorded about the client's characteristics (such as age, gender, ethnicity, and their knowledge of the Dutch language). Information was also recorded about the client's request, the action taken by the $\mathrm{HC}$ advisor, and how clients learned about the HC advisors. The group registration forms contained information about gender, ethnicity and number of participants, the subject, and how it was organized. All quantitative information was imported into Excel by the $\mathrm{HC}$ advisors and analysed using SPSS 13.

A total of 96 interviews were conducted with professionals both directly and indirectly involved in implementing the $\mathrm{HC}$ advisor programme (Table 1). In three districts there were two research periods and in one district there were three. In every district the new research period 
Table 1 Semi-structured interviews were administered to

\begin{tabular}{lc}
\hline Profession (number of persons) & Number of interviews \\
\hline Project leader from Public Health & 9 \\
$\quad$ Service Amsterdam $(n=2)$ & 21 \\
HC advisor coordinators $(n=7)$ & 17 \\
HC advisors $(n=11)$ & 11 \\
Stakeholders in the district councils $(n=6)$ & 8 \\
Health care professionals $(n=6)$ & 10 \\
Social Welfare professionals $(n=10)$ & 9 \\
Stakeholders in migrant organizations $(n=9)$ & 11 \\
Others, such as workers in community & \\
centres and school coordinators $(n=11)$ & \\
\hline
\end{tabular}

started with an interview with the HC advisors themselves and ended with an interview with the project leaders from the Public Health Service Amsterdam. The others who were interviewed were selected by the researcher, based mainly on information from previous interviews. The people who were interviewed came from various disciplines and during each research period interviews were held with at least one person from the district council, a migrant organization, and a health care and welfare organization. All interviews were carried out by the first author, and structured around a topic list. The topic list was based on the research questions and the position of the person interviewed, and was adapted to the information that had been gathered during the previous interviews. The scope of the interviews included questions about (1) their contact with the HC advisor, how it started, and how they experienced this; (2) specific questions on the location and the intervention carried out in the district; (3) the approach of introducing HC advisors; (4) satisfaction with the position, what they had expected beforehand and what had been achieved by introducing the function; and (5) advice for further implementation. Each interview took $\sim 1 \mathrm{~h}$; it was recorded and afterwards fully transcribed ( $n=68$ ) or summarized $(n=28)$. All summarized interviews were returned to the person interviewed to find out if the interpretation was correct. Even though implementation has been different in the four participating districts, we were able to compare the districts and changes that occurred during the pilot.

An additional 14 interviews were administered to the HC advisor's clients to investigate what they did with the information or advice from the $\mathrm{HC}$ advisor and whether they were satisfied. Ten interviews were carried out with clients who had individual contacts. These interviews took place by phone, in the client's language, and were conducted by HC advisors from another district (three Turkish, four Moroccan, and three Dutch). The researcher conducted another four interviews (two Turkish and two Moroccan) in Dutch with clients who took group classes. The questions covered how they knew about the $\mathrm{HC}$ advisors, how the $\mathrm{HC}$ advisors treated them, what the extra value of the language and culture of the $\mathrm{HC}$ advisors was, and what they did with the information they received from the HC advisor. All these interviews were summarized.

\section{Results}

How was the Function of HC Advisor Implemented?

Table 2 presents an overview of the most important characteristics of the HC advisors in the four participating districts. The pilot period started in two districts in 2003 and in the other two districts in 2004. A total of $11 \mathrm{HC}$ advisors were appointed in the four districts and their ethnicity corresponded with the main migrant groups in the districts: there were Moroccan and Turkish HC advisors in three districts, and Ghanaian and Surinamese $\mathrm{HC}$ advisors in one district. All HC advisors worked part-time (between 16 and $24 \mathrm{~h}$ per week). In three districts, the $\mathrm{HC}$ advisors were selected from a pool of bicultural community workers from the Public Health Service Amsterdam. In two districts HC advisors were coordinated by a location coordinator, in one district by a content coordinator from the Public Health Service Amsterdam, and in one district by both a location and a content coordinator.

In three of the districts, the individual contacts took place in an information centre set up especially for this purpose. The opening hours and locations differed between the districts. Those that started first had daily office hours from 9:00 a.m. to 12:00 p.m. (District A) or from 9:00 a.m. to 1:00 p.m. (District B). Because of the low number of individual contacts per day in these districts (a mean of 0.3 clients per hour), District $\mathrm{C}$ decided to have office hours four times a week for $2 \mathrm{~h}$ each at three different locations. District D did not schedule fixed office hours at all.

The original goal in all districts was that $\mathrm{HC}$ advisors should have a front-office position and work for all health care and welfare services in that district. In Districts A, B, 
Table 2 Characteristics of the HC advisor intervention in the four pilot districts in Amsterdam

\begin{tabular}{|c|c|c|c|c|}
\hline District & $\mathrm{A}(\mathrm{OWgm})$ & $\mathrm{B}(\mathrm{ZO})$ & $\mathrm{C}(\mathrm{GV})$ & $\mathrm{D}(\mathrm{ZB})$ \\
\hline \multirow{4}{*}{$\begin{array}{l}\text { Number of } \\
\text { inhabitants [28] }\end{array}$} & 108,533 & 220,880 & 100,477 & 193,079 \\
\hline & $3 \%$ Turkish & $12 \%$ Surinamese & $6 \%$ Turkish & $2 \%$ Turkish \\
\hline & $5 \%$ Moroccan & $3 \%$ Ghanaian & $9 \%$ Moroccan & $3 \%$ Moroccan \\
\hline & $5 \%$ Surinamese & $1 \%$ Turkish and Moroccan & $3 \%$ Surinamese & $2 \%$ Surinamese \\
\hline Pilot period & $2003-2004$ & 2003-2004 & 2004-2005 & 2004-2005 \\
\hline \multirow{3}{*}{$\begin{array}{l}\text { Ethnicity and } \\
\text { gender of the } \\
\text { HC advisors }\end{array}$} & Moroccan (one female) & Ghanaian (one male) & Moroccan (one male, one female) & Moroccan (two females) \\
\hline & Turkish (one female) & Surinamese (two females) & Turkish (one female) & Turkish (one female) \\
\hline & Dutch (one male) & & & \\
\hline $\begin{array}{l}\text { Coordination of } \\
\text { the HC } \\
\text { advisors }\end{array}$ & $\begin{array}{l}\text { Location coordinator and } \\
\text { content coordination } \\
\text { elsewhere }\end{array}$ & Coordination elsewhere & Location coordinator & Location coordinator \\
\hline $\begin{array}{l}\text { Location where } \\
\text { the individual } \\
\text { contacts took } \\
\text { place }\end{array}$ & $\begin{array}{l}\text { Information centre: a back } \\
\text { office in a small unit } \\
\text { of a social welfare } \\
\text { organization }\end{array}$ & $\begin{array}{l}\text { Information centre: a back } \\
\text { office in the building } \\
\text { of a housing association }\end{array}$ & $\begin{array}{l}\text { Information centres: located } \\
\text { in three community centres }\end{array}$ & $\begin{array}{l}\text { 'Office hours' at the } \\
\text { location (virtual } \\
\text { information centre) }\end{array}$ \\
\hline Office hours & 9:00 a.m.-1:00 p.m. daily & 9.00 a.m. $-12: 00$ p.m. daily & $\begin{array}{l}\text { Open } 1 \times 2 \mathrm{~h} \text { at two locations and } \\
2 \times 2 \mathrm{~h} \text { at the other location }\end{array}$ & $\begin{array}{l}\text { Location, time, and } \\
\text { duration differed }\end{array}$ \\
\hline \multirow[t]{3}{*}{ Group classes } & $\begin{array}{l}\text { Maximum of five classes } \\
\text { per group }\end{array}$ & $\begin{array}{l}\text { Maximum of five classes } \\
\text { per group }\end{array}$ & $\begin{array}{l}\text { Maximum of } 20 \text { classes per group } \\
\text { Given by the } \mathrm{HC} \text { advisors }\end{array}$ & $\begin{array}{l}\text { Maximum of five } \\
\text { classes per group }\end{array}$ \\
\hline & Given by the $\mathrm{HC}$ advisors & Given by the $\mathrm{HC}$ advisor & Health care subjects & Given by professionals \\
\hline & Health care subjects & Health care subjects & $\begin{array}{l}\text { In the second pilot year: fewer } \\
\text { classes per group were given, } \\
\text { professionals were invited to } \\
\text { give the group class, and social } \\
\text { welfare subjects were introduced }\end{array}$ & $\begin{array}{l}\text { Health care and social } \\
\text { welfare subjects }\end{array}$ \\
\hline
\end{tabular}

and $\mathrm{C}$ (Table 2), it was planned that the $\mathrm{HC}$ advisors would be a front office in a health care centre. This did not actually happen in any of the districts, because two health care centres were still under construction and in the third the general practitioners (GPs) were opposed to the front-office position of the $\mathrm{HC}$ advisors. In District A, the alternative location was a back-office position in a social welfare organization, in District B this was a backoffice position in a housing cooperation, and in District $\mathrm{C}$ this was a small office in a community centre. Based on the experiences in the other districts, District $\mathrm{D}$ did not introduce fixed office hours in one location-instead, the HC advisors had individual contacts on an outreach basis.

In all of the districts, outreach activities consisted of going to places were many people from ethnic minorities came together, including mosques, migrant organizations, community centres, and homes for the elderly. HC advisors introduced themselves to both individuals and groups and explained what they did, noted down problems, and invited them for individual consultations and group classes. In most cases it took some time before the HC advisors could discuss issues of health, health care or welfare with the clients. One of the stakeholders mentioned ' $a \mathrm{HC}$ advisor goes to places were people come who need some extra help or support, and she talks to people to gain their trust. The first time they talk about nothing special, the next time they talk about small problems or a group class is given, and the third time individuals come with real problems'. The intensity of the outreach activities differed considerably per district and became higher at the end of the pilot period.

The interviews showed that $\mathrm{HC}$ advisors need to know how to answer questions, be knowledgeable about the health care and welfare system (including the local situation), know where and how to find the ethnic minorities and the professionals, speak the language of the target group and the Dutch language, and organize group classes. In the words of one of the stakeholders: ' $a$ HC advisor needs to be a jack of all trades, he needs to know about the health care and welfare system in the district, he needs to understand what his responsibilities are, and he needs to be creative in filling out his function in order to reach and inform ethnic minority groups'. It is important for $\mathrm{HC}$ advisors to know the professionals in order to refer clients, to arrange group classes but also to ask them questions like a HC advisor mentioned 'sometimes I don't know the answer on a question of a client and then I contact the 
professional and give this information to the client'. Also, in one district a HC advisor who met all mentioned competences did not speak the Dutch language fluently enough to communicate with professionals and was for this reason discharged from the project. In addition, HC advisors have to be aware of the limitations of their position and make sure they only provide information and advice, not care. This was confirmed by different health care providers, and especially the social and welfare workers. They mentioned that they were afraid that $\mathrm{HC}$ advisors were giving the care that belongs to their own profession, instead of only giving information and referrals.
Who did the HC Advisors Reach and What was Their Production?

Altogether, the HC advisors had 2,224 individual contacts with 1,500 different residents and gave 576 group classes to a mean number of 17 participants (range 1-47). Most residents reached by individual contacts were female, between 30 and 50 years of age, Turkish or Moroccan (Table 3). Most of the clients were first-generation migrants and almost half of the clients had a minimal knowledge of the Dutch language. From the interviews with professionals and $\mathrm{HC}$ advisors and the observations
Table 3 Information on the individual contacts $(2,224$ contacts with 1,500 residents) a Only data from the first contact were used $(n=1,500)$

${ }^{\mathrm{b}}$ Data from all contacts were used $(n=2,224)$

${ }^{c}$ Only the problems mentioned most frequently were recorded in the table

\begin{tabular}{|c|c|c|c|c|c|}
\hline $\begin{array}{l}\text { District } \\
\text { Number of different residents }{ }^{\mathrm{a}} \\
\text { Total number of contacts }\end{array}$ & $\begin{array}{l}\text { Total } \\
1,500 \\
2,224\end{array}$ & $\begin{array}{l}\text { A } \\
450 \\
576\end{array}$ & $\begin{array}{l}\text { B } \\
379 \\
463\end{array}$ & $\begin{array}{l}\mathrm{C} \\
501 \\
912\end{array}$ & $\begin{array}{l}\mathrm{D} \\
170 \\
273\end{array}$ \\
\hline \multicolumn{6}{|l|}{ Gender $^{\mathrm{a}}(\%)$} \\
\hline Female & 71 & 70 & 66 & 71 & 80 \\
\hline \multicolumn{6}{|l|}{$\operatorname{Age}^{\mathrm{a}}(\%)$} \\
\hline$<30$ years & 16 & 19 & 14 & 18 & 9 \\
\hline $30-50$ years & 44 & 42 & 49 & 41 & 46 \\
\hline$>50$ years & 31 & 31 & 21 & 40 & 31 \\
\hline Unknown & 9 & 8 & 16 & 1 & 14 \\
\hline \multicolumn{6}{|l|}{ Ethnicity $^{\mathrm{a}}(\%)$} \\
\hline Turkish & 33 & 37 & 0 & 45 & 65 \\
\hline Moroccan & 23 & 19 & 1 & 47 & 31 \\
\hline Ghanaian & 9 & 0 & 33 & 0 & 0 \\
\hline Surinamese & 8 & 5 & 26 & 0 & 1 \\
\hline Dutch & 12 & 23 & 11 & 2 & 0 \\
\hline Other non-Western migrants & 9 & 9 & 17 & 5 & 1 \\
\hline Other Western migrants & 1 & 2 & 1 & 0 & 0 \\
\hline Unknown & 5 & 5 & 11 & 1 & 2 \\
\hline First generation ${ }^{\mathrm{a}}(\%)$ & 81 & 64 & 75 & 94 & 98 \\
\hline Minimal knowledge of the Dutch language ${ }^{\mathrm{a}}(\%)$ & 42 & 27 & 27 & 56 & 73 \\
\hline \multicolumn{6}{|l|}{ Heard about $\mathrm{HC}$ advisors from ${ }^{\mathrm{a}}(\%)$} \\
\hline $\mathrm{HC}$ advisors themselves & 40 & 0 & 0 & 45 & 79 \\
\hline Word of mouth & 18 & 16 & 14 & 26 & 9 \\
\hline Professional & 10 & 11 & 5 & 15 & 1 \\
\hline Local paper, flyer, or poster & 5 & 12 & 4 & 1 & 0 \\
\hline Other & 23 & 35 & 33 & 10 & 6 \\
\hline Unknown & 4 & 6 & 3 & 3 & 5 \\
\hline \multicolumn{6}{|l|}{ Clients' problems ${ }^{\mathrm{b}, \mathrm{c}}(\%)$} \\
\hline Health & 15 & 13 & 14 & 13 & 31 \\
\hline Financial & 15 & 17 & 21 & 8 & 25 \\
\hline Housing & 11 & 6 & 14 & 7 & 26 \\
\hline Psychological/psychosocial & 9 & 9 & 2 & 14 & 2 \\
\hline Legal (laws/legislation) & 8 & 12 & 0 & 9 & 7 \\
\hline \multicolumn{6}{|l|}{ Action by $\mathrm{HC}$ advisor ${ }^{\mathrm{b}}(\%)$} \\
\hline Give information and advice & 41 & 39 & 45 & 44 & 32 \\
\hline Referral to another party & 56 & 61 & 54 & 50 & 68 \\
\hline Consultation with $\mathrm{HC}$ advisor, professional and client & 3 & 0 & 1 & 6 & 0 \\
\hline
\end{tabular}


Table 4 Information on group classes

\begin{tabular}{|c|c|c|c|c|c|}
\hline $\begin{array}{l}\text { District } \\
\text { Number }\end{array}$ & $\begin{array}{l}\text { Total } \\
603\end{array}$ & $\begin{array}{l}\text { A } \\
135\end{array}$ & $\begin{array}{l}\text { B } \\
17\end{array}$ & $\begin{array}{l}\text { C } \\
374\end{array}$ & $\begin{array}{l}\text { D } \\
77\end{array}$ \\
\hline \multicolumn{6}{|l|}{ Gender $(\%)$} \\
\hline Female participants & 73 & 89 & 71 & 66 & 82 \\
\hline \multicolumn{6}{|l|}{ Ethnicity $(\%)$} \\
\hline Turkish & 36 & 58 & 0 & 29 & 38 \\
\hline Moroccan & 58 & 42 & 0 & 71 & 38 \\
\hline Surinamese & 0 & 0 & 17 & 0 & \\
\hline African & 2 & 0 & 59 & 0 & \\
\hline Mixed nationalities & 4 & 0 & 24 & 0 & 24 \\
\hline \multicolumn{6}{|l|}{ Subjects $^{\mathrm{a}}(\%)$} \\
\hline Psychosomatic complaints & 14 & 16 & 41 & 17 & \\
\hline Female complaints & 9 & 21 & 1 & 7 & \\
\hline Healthy food & 7 & 11 & 12 & 7 & \\
\hline Psychological problems (depression) & 7 & 8 & 0 & 9 & \\
\hline Anatomy & 6 & 3 & 0 & 7 & \\
\hline Health care in the Netherlands & 6 & 0 & 0 & 8 & 0 \\
\hline Social welfare subjects & & 0 & 0 & 2 & 47 \\
\hline
\end{tabular}

a Only the problems mentioned most frequently were recorded in the table

made, it appeared that this percentage was even higher among the participants of the group classes. As with the individual contacts, those who attended the group classes were also more often females and Turkish and Moroccan residents (Table 4).

The location of the information centres had a strong influence on the number of clients and what kind of questions they had. Lower numbers of clients were seen in Districts A and B, which was probably caused by the 'invisible' location of the information centres behind the front desk of another organization (a social welfare organization and a housing cooperation) were the clients had to present themselves first to the employee at the front desk. Also, the number of people walking in and out of the location where the information centre was located had an effect on the number of clients. For example, in District C, $84 \%$ of the clients were seen during the office hours of the busiest community centre, while the other $16 \%$ were seen during the same number of office hours in other, less busy, community centres.

In all of the districts taken as a whole, most of the questions residents asked during individual contacts were about health, financial, housing, psychological/psychosocial, and legal (laws/legislation) problems (Table 3). The kind of problems presented by clients was related to the location of the information centre. For example, the $\mathrm{HC}$ advisors working in the information centre situated in a welfare organization received more questions about welfare subjects (District A), while those working in a housing cooperation received more questions on housing (District B).

Although in all districts posters and leaflets were used, the registration forms showed that most clients had learned about the $\mathrm{HC}$ advisor through the $\mathrm{HC}$ advisors themselves $(40 \%)$, via private contacts $(18 \%)$, or had heard about them from professionals (10\%) (Table 3). In District D, where all individual contacts took place on an outreach basis, almost all clients had heard about the $\mathrm{HC}$ advisors from the HC advisors themselves (79\%). Compared to what was suggested in the interviews with the HC advisors and their coordinators, in all districts, only a few clients had heard about the HC advisors through leaflets, posters, or local news papers.

More than half of the contacts HC advisors had with their clients resulted in referrals to other parties, in most cases professionals. Most of the referrals were to social counsellors, GPs, social workers, and housing professionals. Nine percent of the clients were referred to group classes in the district.

In all of the districts, the subjects of the group classes were determined by the $\mathrm{HC}$ advisors in close consultation with migrant organizations or participants of the group. Because three of the districts had HC advisors with a bicultural community health care workers background, most of the educational themes were related to health care. Subjects covered most often were psychosomatic complaints, female complaints, healthy food, psychological problems (depression), anatomy, and organization of health care in the Netherlands.

In District $\mathrm{D}$, the $\mathrm{HC}$ advisors had no bicultural community workers background and less basic knowledge about health care subjects. In this district they decided to invite professionals to give the group classes. The HC advisors set up the groups, provided information and support to the professional, and if necessary translated the information into the language and/or culture of the group during the class. Those most often invited were health care insurance professionals, social workers, social counsellors, and GPs. Professionals and stakeholders evaluated this approach as being very successful. They stated that residents and professionals were able to get to know and understand each other, professionals were able to answer the residents' questions directly, and the professionals themselves were able to correct inaccurate expectations of the health care system. For example a professional mentioned that 'residents can see that a shrink is also a normal person and that a compulsory school attendance clerk is not a bogyman'. In addition, the stakeholders interviewed mentioned that it was also possible to deal with health care subjects more thoroughly and introduce social welfare subjects. As a result of this success, District C started to introduce professionals in the second year of the pilot. 
Another task of the $\mathrm{HC}$ advisor is to inform the district council and professionals about special common problems ethnic minorities experience. An example of this is that, based on information provided by the HC advisors, the local government introduced new activities to decrease the long waiting times for social counsellors.

Clients who were interviewed said they were satisfied with their contact with the $\mathrm{HC}$ advisor. In addition, more than half of them were actually taking action to do something about their problem. Participants in the group classes also mentioned they were happy with their newly acquired information and that they told their friends and family about what they had learned.

Which Features are Needed to Make the Function of HC Advisor Successful?

Several factors seem to contribute to the success of the function of $\mathrm{HC}$ advisor. These factors are listed in Box 1 and include the ethnicity of $\mathrm{HC}$ advisors, having a male $\mathrm{HC}$ advisor, having a location coordinator, conducting outreach work, creating possibilities for individual contacts, giving group classes, and inviting health care and welfare professionals to give the group classes. Furthermore, individual contacts need to take place in a location that is familiar and easily accessible, and HC advisors need to be integrated into the existing health care and welfare services; there must also be enough commitment from stakeholders and professionals.

When looking at the clients reached by the $\mathrm{HC}$ advisor, it became clear that the ethnic background of the $\mathrm{HC}$ advisors had an enormous influence on the ethnic background of their clients (Table 3). For example, in District A there was no Moroccan $\mathrm{HC}$ advisor during 1 year of the pilot, and although the number of Moroccans in this district was higher compared with Turkish (5 vs. 3\%), many more Turkish people were reached (37 vs. 19\%). In addition, HC advisors and professionals mentioned that advisors with the same ethnic background know more about the problems ethnic minorities encounter as a consequence of their migration. Another benefit they mentioned is that it is easier for the $\mathrm{HC}$ advisors to reach ethnic minority groups who are harder for the professionals to reach. Reasons given by professionals for not being able to reach ethnic minorities were language barriers, cultural differences, a lack of confidence of the ethnic minority group, and sometimes the absence of being able to gain entrance to these groups. In addition, because of their ethnic background and investment of time, $\mathrm{HC}$ advisors were able to build a relationship of trust with ethnic minority groups. From the interviews, it appeared that this trust is very important in motivating minorities to take part in group classes and to take action to solve their own problems based on information provided by the professional or $\mathrm{HC}$ advisor.

Working with a male $\mathrm{HC}$ advisor seems to help to reach males. From the registration and interviews it appeared that fewer males (and Moroccan males in particular) were reached during the pilot. The attendance of Moroccan males was much higher in the district where there was a male Moroccan $\mathrm{HC}$ advisor (District $\mathrm{C}$ ). Of all residents who were reached during the pilot, $81 \%$ of all individual and $89 \%$ of all group contacts with Moroccan males took place in this district.

Since the coordination was organized differently in the four participating districts, it became clear that, especially in a pilot setting, good coordination at the location itself is very important for success. Circumstances in one district (District B) meant that the coordinator was located elsewhere. The coordinator mentioned 'she didn't have any control over the situation' and the HC advisors in that district said they 'felt as if they were left on their own'. In addition, from observations it appeared that the $\mathrm{HC}$ advisors became less motivated during the pilot. The

Box 1 Which potential success factors allow HC advisors to improve access to health care and welfare services for ethnic minorities?

Ethnic background of HC advisors should correspond with the migrant population (language and culture).

Male migrants can be reached more easily by a male $\mathrm{HC}$ advisor.

To reach migrants, $\mathrm{HC}$ advisors need to conduct outreach work.

$\mathrm{HC}$ advisors need a coordinator at the location itself.

When individual contacts take place in an office during office hours, the location must be easily accessible to migrants. The location also has an influence on the kinds of problems clients present.

The combination of individual contacts and organizing group classes seems to be an efficient way to reach and provide information to migrants.

To inform groups about the health care and welfare system, $\mathrm{HC}$ advisors can give the group classes themselves, but a successful alternative to this is to invite professionals to give the classes.

$\mathrm{HC}$ advisors need to be integrated into the existing health care and welfare services.

Enough attention needs to be paid to the commitment of all involved parties.

There must be a fitting back-office to refer inhabitants to. 
coordinators in the other districts who worked on location mentioned that, especially at the start of the project, they were needed to coordinate the $\mathrm{HC}$ advisors. In a later phase of the pilot they invested most of their time in organizing contacts with the professionals and stakeholders.

To reach ethnic minorities, it seems to be important to conduct outreach work. Also, when organizing office hours, the office needs to be situated in a visible location, one that is easily accessible for ethnic minorities. During the first year of the pilot, Districts A and B gave more attention to the individual contacts during office hours. During the second year of the pilot, more attention was paid to outreach activities like group classes, which resulted in more client contacts on both an individual and group basis. Also, the districts that started later (C and D) organized fewer office hours and more outreach activities.

It appeared from interviews that the combination of individual contacts and group classes was good for reaching and informing ethnic minorities as well as answering questions, as well as gathering information about the specific problems in the ethnic minority groups. Because $\mathrm{HC}$ advisors gained trust from the minorities, they were able to find the 'question behind the question' during individual contacts and refer their clients to the right health care and welfare professionals. During these individual contacts they also gained more insight into the problems ethnic minority groups have. Also, during group classes it was possible to provide general information about relevant health care and welfare subjects and answer general questions.

From the interviews with stakeholders and professionals it became clear that in addition to the group classes given by the $\mathrm{HC}$ advisors themselves, the group classes given by professionals were considered to be successful. The professionals interviewed were positive about the fact that $\mathrm{HC}$ advisors could introduce them to the ethnic minority groups who are normally hard to reach, which lowered the contact barrier for both the professionals and the ethnic minorities. Professionals mentioned that during these group classes, $\mathrm{HC}$ advisors were able to translate the information not only into the language of the ethnic minorities, but also in terms of their culture. Furthermore, HC advisors were able to find out from the groups specific problems minorities have with the Dutch health care system. Additionally, stakeholders mentioned that this approach makes it possible to cover a broad variety of subjects. Finally, the professionals stated that $\mathrm{HC}$ advisors were able to inform them about specific cultural aspects and the economic position of the ethnic minorities and the specific problems these groups face in Dutch society.

Integration into the existing health care and welfare services and commitment from professionals and stakeholders are important for the functioning of the $\mathrm{HC}$ advisors and to create a basis for further institutionalization. In three of the four districts, the implementation was hampered by a lack of ongoing commitment of the parties involved (e.g. health care and welfare providers, migrant organizations) and a lack of integration into existing health care and welfare facilities. For this reason, HC advisors were not always known and accepted by professionals and it became clear from interviews with professionals that the function of $\mathrm{HC}$ advisors was not always clear, nor what professionals could expect from them. HC advisors themselves mentioned that they had to introduce themselves over and over again to professionals from the same organisation.

One of the consequences of this lack of integration was that there was almost no contact with or easy access to the back office with professionals for the $\mathrm{HC}$ advisors and their clients. The HC advisors and professionals interviewed mentioned that a well-organized relationship with the back office is especially important for these minority groups, because they have a low degree of literacy and ability to access services on their own. As a consequence, HC advisors were persuaded to give care instead of information and referral only, which resulted in long client contacts, clients who kept coming back, and a high (emotional) workload for the HC advisors. In the district in which the $\mathrm{HC}$ advisors were integrated into the health care and welfare system there was more commitment among all parties, which finally resulted in continuing the function for at least 4 years.

\section{Discussion}

By using outreach activities and individual contacts, HC advisors were able to reach ethnic minority groups, obtain insight into their problems and inform them about health care and welfare services and topics. In this way they helped them understand and gain trust in health care and welfare services and professionals and so improved knowledge and health literacy $[2,3,5,7-10]$. Comparing the activities of the $\mathrm{HC}$ advisor with the model of Brach et al. [9], that specifies the activities that can be used to reduce racial and ethnic disparities in health care, the function of $\mathrm{HC}$ advisor corresponds with several of these, including the introduction of special activities to recruit ethnic minorities, use of community workers, provision of an interpreter service and provision of culturally competent health promotion. As previous studies indicate that these are potentially effective interventions to reduce ethnic inequalities in health (care), $\mathrm{HC}$ advisors are likely to contribute to a better health status and well being of ethnic minority groups.

Success factors that helped the $\mathrm{HC}$ advisors reach ethnic minorities, provide them with information, and lower the 
barriers to health care and welfare services were the ethnic background of the $\mathrm{HC}$ advisor, introduction of both a female and a male $\mathrm{HC}$ advisor, and creating possibilities for individual contacts at popular locations, and conducting outreach work including individual contacts and group classes. Furthermore, integration of the position into the existing services and the commitment of both stakeholders and professionals need sufficient and ongoing attention.

The ethnic background of the HC advisors appeared to be important to remove both language and cultural barriers in reaching and providing information to ethnic minorities and gaining their trust [14-19, 27]. Both this study and previous research show that second-generation minorities who do speak the Dutch language also have communication problems caused by their culture $[15,17]$. In addition to their ability to translate in terms of culture and language, $\mathrm{HC}$ advisors use their own ethnic background to understand the problems ethnic minorities have after migration and to reach these groups [9]. During this pilot, the ethnic background of the HC advisors was geared to the largest minority groups. In 2007, $19 \%$ of the inhabitants in the Netherlands were from ethnic minorities, more than half of whom were non-Western [28]. In Amsterdam, 34\% of the inhabitants are non-Western minorities and of this group, almost $75 \%$ are form Surinamese, Moroccan, or Turkish decent [24]. For this reason, three of the four participating districts chose for Turkish and Moroccan HC advisors and one district chose for Surinamese HC advisors.

When office hours for individual consultations are introduced, special attention need to be paid to the location. It needs to be a place which is comfortable and easy to reach by minorities, for example a community centre. This seems to be important given the relatively high number of clients which were seen on such locations and the fact that people mainly knew about the position from the $\mathrm{HC}$ advisor themselves. Additionally, the type of questions clients had corresponded with the function of other services on that location. Since the expertise of all HC advisors were comparable, this might point out that this was the most urgent question of the client. On the other hand, it might also say that the contacts with this client arose coincidentally and was not intended by the client on forehand.

Another important key factor for the position's success are the outreach activities for reaching and providing information to clients from ethnic minority groups by giving individual advice and information or group classes [7]. As a direct result from the action research, districts started to invest more time in outreach activities instead of office hours after the first pilot year. During these outreach activities, HC advisors go to the places were minorities gather, get to know them and gain their trust, find out what information they need, and provide information and advice.
As was already known from previous studies, our study also shows that this kind of outreach is needed because minorities are less flexible with regard to going to locations where they can gain information, and they are not used to reading folders, papers, or posters [2, 7, 10, 29].

Individual contacts can be used in two ways, namely, to gain trust from individuals or to use this trust to help individuals get answers to their questions, and provide information and advice that is in line with the person's needs [5, 9, 29]. Furthermore, group classes can besides gaining trust and providing information directed at the problems minorities face, also be used to catch the attention from people who are normally not reached.

Besides giving group classes on specific health care subjects as most community workers do, $\mathrm{HC}$ advisors can inform minorities about a wide range of different subjects and services, including welfare subjects, and what they can expect from health care and welfare professionals in general $[2,4,7,14,16,18,29]$. In this way, knowledge about and trust in services and professionals might be improved, something that previous studies showed to be important determinants for health care quality [2, 4]. During the pilot, an extra dimension was given to the group classes by inviting professionals to give the classes. Minorities and professionals can get to know and understand each other, professionals can answer the residents' questions directly, and the professionals themselves are able to correct inaccurate expectations of health care and welfare. In addition, the $\mathrm{HC}$ advisor can introduce a much broader spectrum of subjects. During this study, this approach was evaluated as being very successful, but until now not much has been written about this way of organizing group classes for minority groups.

As we already know from other studies about introducing new positions, adapting and integrating the function into the existing health care and welfare system needs sufficient and ongoing attention [30]. Only then can both professionals and $\mathrm{HC}$ advisors take optimal advantage of each other's knowledge and capacities. In addition, a well organized and good functioning organization with professionals (the back office) is needed to refer clients to and answer questions from the $\mathrm{HC}$ advisor. Previous studies have shown that a direct referral to professionals is especially relevant for this group, because of their low level of literacy [5, 31]. Finally, to actually institutionalize the HC advisor, enough attention needs to be paid to the commitment of professionals and other stakeholders [30]. In three of the four districts, the adaptation activities stopped after the implementation phase and as a consequence the position of $\mathrm{HC}$ was not continued, even though especially one district received a very positive evaluation. In the fourth district, enough attention was given to commitment and institutionalization, and the position was continued for at 
least another 4 years. In addition, as a direct result of the pilot and the underlying research, a discussion is currently underway about how to reintroduce the $\mathrm{HC}$ advisor position in the districts in Amsterdam with a high number of minorities. In fact in two new districts the function was implemented in September 2008.

Throughout our whole study it appeared that gaining trust from the ethnic minorities and helping them to obtain confidence in the health care and welfare system is an important task of the $\mathrm{HC}$ advisor. Feelings of distrust in health care and welfare services in these groups are probably partly caused by their migration history and the experiences with a different health care system in their home country. It might, however, also be related to a growing ethnic tension in the Netherlands during the last decade. The growing negative publicity about ethnic minority (like the Moroccan, Turkish, Surinamese and Antilleans) or religious (Islam) groups as well as the growth of right wing parties in parlement resulted in feelings of unsafety and increased discrimination towards ethnic minorities, leading to a growing distrust from both parties, ethnic minorities and ethnic Dutch, toward each other. Beside the direct effect $\mathrm{HC}$ advisors might have on gaining trust in individuals, the function might also contribute to improve feelings of trust by showing that the health care and welfare system is willing to offer tailored services to ethnic minority groups.

A few limitations of this study should be considered. The underlying research is participatory action research, and as a consequence, the researcher was involved in developing the position of $\mathrm{HC}$ advisors. The possible influence of this involvement on the validity of the research was compensated by intensive reflection on the research in an academic setting [22, 23]. Additionally, the four districts that participated in the pilot developed and adapted the position of $\mathrm{HC}$ advisors in their district partly based on the research results in the other districts.

As shown in our study, introducing HC advisors seems to be a good strategy for bridging the gap between ethnic minority groups and health care and welfare services. Besides bridging cultural and language barriers, they appeared to be able to reach and inform minorities about a broad spectrum of health care and welfare subjects and help them gain trust in and find their way to health care and welfare services. HC advisors are able to cover a broad spectrum of subjects, because they work for all health care and welfare services and use the back office to refer clients to, answer questions they are not able to answer, and invite professionals to give group classes. As the next step, an effect evaluation should be conducted to actually prove the extent of the effects on improved access, health literacy, empowerment, and social norms $[9,13,31]$.
Acknowledgments The authors gratefully acknowledge the funding provided by ZonMW, the Netherlands organisation for health research and development.

Open Access This article is distributed under the terms of the Creative Commons Attribution Noncommercial License which permits any noncommercial use, distribution, and reproduction in any medium, provided the original author(s) and source are credited.

\section{References}

1. Stronks, K., Ravelli, A. C., \& Reijneveld, S. A. (2001). Immigrants in the Netherlands: Equal access for equal needs? Journal of Epidemiology and Community Health, 55(10), 691-692.

2. Doescher, M. P., Sacer, B. G., Franks, P., \& Fiscella, K. (2000). Racial and ethnic disparities in perceptions of physician style and trust. Archives of Family Medicine, 9, 1156-1163.

3. Lindstrom, M., Sunquist, J., \& Ostergren, P. O. (2001). Ethnic differences in self-reported health in Malmo in southern Sweden. Journal of Epidemiology and Community Health, 55, 97-103.

4. Andrews, J. O., Felton, G., \& Wewers, M. E. (2004). Use community health workers in research with ethnic minority women. Journal of Nursing Scholarship, 36(4), 358-365.

5. Gany, F. M., Herrera, A. P., Avallone, M., \& Changrani, J. (2006). Attitudes, knowledge, and health-seeking behaviour of five immigrant minority communities in the prevention and screening of cancer: A focus group approach. Ethnicity and Health, 11(1), 19-39.

6. Cooper, L. A., Hill, M. N., \& Powe, N. R. (2002). Designing and evaluating interventions to eliminate racial and ethnic disparities in health care. Journal of General Internal Medicine, 7, 477-486.

7. Witmer, A., Seifer, S. D., Finocchio, L., Leslie, L., \& O’Neil, E. H. (1995). Community health workers: Integral members of the health care work force. American Journal of Public Health, $85(8), 1055-1058$.

8. ten Have, M. L., \& Bijl, R. V. (1999). Inequalities in mental health care and social services utilization by immigrant woman. European Journal of Public Health, 9, 45-51.

9. Brach, C., \& Fraser, I. (2000). Can cultural competence reduce racial and ethnic disparities? A review and conceptual model. Medical Care Research and Review, 57(Suppl. 1), 181-217.

10. Sundquist, J. (2001). Migration, equality and access to health care services. Journal of Epidemiology and Community Health, 55(10), 701-707.

11. Rhodes, P., Nocon, A., \& Wright, J. (2003). Access to diabetes services: The experiences of Bangladeshi people in Brandford, UK. Ethnicity and Health, 8(3), 171-188.

12. Programme Committee on Socio-Economic Inequalities in Health Second Phase. (2001). Reducing socio-economic inequalities in health. Final report and recommendations from the Dutch Programme Committee on Socio-Economic Inequalities in HealthSecond Phase. The Hague: Netherlands Organisation for Health Research and Development (ZonMw).

13. Stronks, K., \& Mackenbach, J. P. (2006). Evaluating the effect of policies and intervention to address inequalities in health: Lessons from a Dutch programme. European Journal of Health, 16(4), 346-353.

14. Voorham, A. J. J., Uitewaal, P. J. M., \& Bruijnzeels, M. (2002). Het effect van voorlichting eigen taal aan diabetes patiënten een experiment in de eerste lijn. Tijdschrift voor gezondheidswetenschappen, 80(8), 514-520. 
15. Nierkens, V., Krumeich, A., de Ridder, A., \& van Dongen, M. (2002). The future of intercultural mediation in Belgium. Patient Education and Counselling, 46(4), 253-259.

16. Joosten-van Zwanenburg, E., Hoop, de T., \& Kocken P. (2004). Bruggen bouwen: Samenwerking tussen huisartsen en allochtone zorgconsulenten in de zorg aan Turkse en Marokkaanse vrouwen met stressgerelateerde pijnklachten. Rotterdam Public Health Service (GGD Rotterdam). Available from: http://www.ggd.rotter dam.nl.

17. Bohmer, F. (2006). Een kwestie van cultuur: Allochtone zorgconsulenten in Nijmeegs kinderziekenhuis doet goed werk (praktijk). Medisch Contact, 61(28), 1176-1178.

18. Reijneveld, S. A. (1998). Reported health, lifestyles, and use of health care of first-generation immigrants in the Netherlands: Do socioeconomic factors explain their adverse position? Journal of Epidemiology and Community Health, 52, 298-304.

19. Karliner, L. S., Jacobs, E. A., Chen, A. H., \& Mutha, S. (2007). Do professional interpreters improve clinical care for patients with limited English proficiency? A systematic review of the literature. Health Service Research, 42(2), 727-754.

20. Raad voor de Volksgezondheid (Council for Public Health and Health Care RVZ). (2002). Interculturalisatie van de gezondheidszorg zorg. Advies uitgebracht door de Raad voor de Volksgezondheid en Zorg aan de minister van Volksgezondheid, Welzijn en Sport. Zoetemeer. Available from: http://www.rvz.ne.

21. van der Lucht, F., \& Verkleij, H. (2001). Gezondheid in de grote steden. Achterstanden en kansen. Themarapport van de Volksgezondheid Toekomst Verkenning 2002. National Institute for Public Health and the Environment (RIVM) report. Houten: Bohn Stafleu Van Loghum.

22. Ovretveit, J. (1998). Chapter 2: Evaluation purpose, theory and perspective and Chapter 7: Developmental evaluation. In: Evaluating health interventions (pp. 23-47 and 121-136). Buckingham/Philadelphia: Open University Press.

23. Baum, F., MacDougall, C., \& Smith, D. (2006). Participatory action research. Journal of Epidemiology and Community Health, 60(10), 854-857.

24. Onderzoek en Statistiek [Department of Research and Statistics], Amsterdam. (2007). 'City districts in figures' [Stadsdelen in cijfers] and 'Origin and groupings' [Herkomst en groeperingen]. Available from: http://www.os.amsterdam.nl/english/.

25. Creswell, J. W. (2003). Chapter 11: Mixed methods procedures. In J. W. Creswell (Ed.), Research design: Qualitative, quantitative, and mixed methods approaches (2nd ed., pp. 208-226). Thousand Oaks, CA: Sage Publications.

26. Hesselink, A. E., Stronks, K., \& Verhoeff, A. P. (2005-2007). Six evaluation reports about ethnic health care advisors in information centres for health care and welfare in four districts of Amsterdam [in Dutch: Evaluatie van het Informatiecentrum Wijkgerichte Zorg en Welzijn en de allochtone zorgadviseurs in vier stadsdelen van Amsterdam] [online]. Epidemiologie, Documentatie \& Gezondheidsbevordering. Amsterdam Public Health Service (GGD Amsterdam). Available from: http://www.gezond. amsterdam.nl.

27. Reijneveld, S. A., Westhoff, W. H., \& Hopman-Rock, M. (2003). Promotion of health and physical activity improves the mental health of elderly immigrants: Results of a group randomised controlled trail among Turkish immigrants in the Netherlands aged 45 and over. Journal of Epidemiology and Community Health, 57, 405-411.

28. Statistics Netherlands [Centraal Bureau voor de Statistiek], CBS statline. (2007). Population figures [Bevolking, Kerncijfers]. Available from: http://www.stateline.cbs.nl.

29. Wiking, E., Johansson, S., \& Sunquist, J. (2004). Ethnicity, acculturation, and self- reported health. A population-based study among immigrants from Poland, Turkey, and Iran in Sweden. Journal of Epidemiology and Community Health, 58, 574-582.

30. Fleuren, M. A. H., Wiefferink, C. H., \& Paulussen, T. G. W. M. (2002). Belemmerende en bevorderende factoren bij de implementatie van zorgvernieuwingen in organisaties. Leiden: TNO Preventie en Gezondheid.

31. Nutbeam, D. (2000). Health literacy as a public health goal: A challenge for contemporary health education and communication strategies into the twenty-first century. Health Promotion International, 5(3), 259-267. 